\title{
Hip complaints differ across age and sex: a population-based reference data for the Hip disability and Osteoarthritis Outcome Score (HOOS)
}

\author{
A Sundén ${ }^{1 *}$ D , K Lidengren ${ }^{1}$, E M Roos ${ }^{2}$, L S Lohmander ${ }^{3}$ and E Ekvall Hansson ${ }^{1,4}$
}

\begin{abstract}
Background: The Hip disability and Osteoarthritis Outcome Score (HOOS) is a self-administered hip-specific questionnaire intended to evaluate symptoms and functional limitations, and it is commonly used to evaluate interventions in individuals with hip dysfunction or hip osteoarthritis. The HOOS consists of 43 questions in five subscales: Pain, Symptoms, Function in daily living, Function in sport and recreation and Hip-Related Quality of Life. This study aimed to establish population-based reference values for the HOOS and to describe the variation of hiprelated symptoms in an adult population.

Methods: The HOOS questionnaire was mailed to 840 individuals aged 18-84 years randomly retrieved from a national population record for the Skåne region of Southern Sweden.

Results: The overall response rate was $67 \%$. Older women and men consistently reported more hip-related complaints than those younger. There were significant differences between the oldest and the youngest age groups in all five subscales in women and men.

Conclusions: Hip-related pain, symptoms, activity of daily life and quality of life varied with age and sex in this population-based cohort. Our findings show the importance of using age- and sex-matched reference values for evaluation of outcomes after interventions due to hip-related problems.
\end{abstract}

Keywords: Osteoarthritis, Hip, HOOS, Reference values

\section{Background}

Multi-item disease-specific self-reported outcome measures have been recommended to assess the effect of interventions on hip injury and hip osteoarthritis (OA) [1]. The Hip disability and Osteoarthritis Outcome Score (HOOS) was established as an extension of The Western Ontario and McMaster Universities Arthritis Index (WOMAC) by adding new questions based on over one hundred interviews with individuals with hip disability [2-4]. The HOOS was constructed to better fit, as compared to the WOMAC, patients' expectations of more demanding physical function - for example for younger individuals and individuals in an early stage of the disease [5]. The

\footnotetext{
* Correspondence: anne.sunden@med.lu.se

${ }^{1}$ Department of Health Sciences, Lund University, Lund, Sweden

Full list of author information is available at the end of the article
}

HOOS has been recommended specifically for the evaluation of patients with hip OA undergoing non-surgical or surgical interventions such as total hip replacement (THR) $[2,6,7]$. When assessing individuals with hip OA the psychometric properties of the HOOS have shown adequate test-retest reliability, floor and ceiling effects, and construct validity. The HOOS has also been validated for short- and long-term follow-up studies of patients with primary OA assigned for THR $[2,5,8]$. Thus, the HOOS has psychometric properties that enable researchers and clinicians to use it with confidence [5, 9-11].

To facilitate the interpretation of responses to interventions and in clinical decision-making, a comparison with appropriate reference values is essential [12]. However, there is a lack of reference data for many clinical measures from the general population, in particular with regard to

(c) The Author(s). 2018 Open Access This article is distributed under the terms of the Creative Commons Attribution 4.0 International License (http://creativecommons.org/licenses/by/4.0/), which permits unrestricted use, distribution, and reproduction in any medium, provided you give appropriate credit to the original author(s) and the source, provide a link to the Creative Commons license, and indicate if changes were made. The Creative Commons Public Domain Dedication waiver (http://creativecommons.org/publicdomain/zero/1.0/) applies to the data made available in this article, unless otherwise stated. 
the relationship between demographic factors and self-reported hip status [12].

Our study aimed to establish reference values for the HOOS, and to describe the age- and sex-related variation of hip-related pain, other symptoms, functional difficulties during daily life as well as sport and recreation, and hip related quality of life.

\section{Methods}

A population-based sample was randomly chosen from a national population record for the Skåne region (Scania) of Southern Sweden. Everyone in Sweden is registered in the National Population Records, which is updated every six weeks. About $1 / 9$ of the Swedish population is in Skåne - at the time of this study approximately 770,000 individuals aged over 18. Skåne includes both urban and rural communities. A simple sampling method was used. From the national population record we requested a random sample of 60 men and 60 women from each of seven age groups $(18-24,25-34,35-44,45-54,55-64,65-74$ and 75-84), for a total of 840 individuals. These age groups were then collapsed into four age groups (18-34, 35-54, 55-74, and 75-84). This selection of age groups followed the same procedure as an earlier study on reference values for the Knee injury and Osteoarthritis Outcome Score (KOOS) [13]. The number chosen $(60$ men+60 women /10-year stratum) was based on experience from clinical studies using the KOOS, where a clinically significant difference of 10 points has been observed in different populations after interventions [14-16]. No other demographic characteristics besides age and sex were obtained. The HOOS questionnaire was mailed together with a cover letter explaining the purpose of the study, and a prepaid return envelope. The non-responders were reminded twice with the same cover letter as the first one together with a new HOOS questionnaire and a new prepaid return envelope.

\section{Questionnaire}

The HOOS is a self-administered disease-specific questionnaire intended to evaluate symptoms and functional limitations related to hip osteoarthritis. The questionnaire is free of charge and can be downloaded from the KOOS website [17]. The HOOS is available in more than 20 languages; in this study the Swedish version was used. In this study, the Swedish version was used [17]. The HOOS is an adaptation of the KOOS [17-20]. The version used in this study was the HOOS LK1.0 which contains 43 items in five subscales: Pain (Pain) (10 items), Symptoms (Symptoms) (4 items), Function in daily living (ADL) (21 items), Function in sport and recreation (Sport/Rec) (3 items) and Hip-Related Quality of Life (QOL) (5 items). A Likert scale of five response options is used for each item [17].

The HOOS LK1.0 has been revised, and the most recent form the HOOS LK2.0 consists of 40 items assessing the five separate patient-relevant subscales [17]. The HOOS LK2.0 was not available at the time the data of the present study was collected.

\section{The HOOS scoring}

Standardized answer options were given (5 Likert boxes) and each item assigned a score from 0 to 4 . The scores from all items within a subscale were then summed. A separate score was calculated for each of the five subscales and then transformed to a 0 to 100 scale where 100 represented the best result. Traditionally in orthopedics, a score of 100 indicates no problems and 0 indicates extreme problems. The normalized score is transformed to meet this standard [17, 19]. In the present study, if the number of missing items was more than $50 \%$ in a subscale, the response was considered invalid and no subscale score was calculated in accordance with the HOOS 2013 scoring manual [17].

\section{Statistical analysis}

The statistical analyses were performed with SPSS 21.0 for Windows (SPSS Inc., Chicago, Il, USA). To increase power, compensate for non-responders, and minimize the number of comparisons made, the original seven age groups were collapsed into four age groups when testing for differences due to age and sex. Reference values for the KOOS were similarly reported [13]. Analysis of variance, ANOVA, was used to examine differences between groups. A post hoc test with Bonferroni correction was used to protect from Type 1 Error due to multiple comparisons. Some of the data were not normally distributed, but the sample size in each group was large enough $(n \geq 30)$ to apply the central limit theorem, which gives normally distributed sample means [21].

\section{Results}

Eight hundred and forty questionnaires were sent out, of which 45 were returned undelivered because the intended recipient was deceased or had moved to an unknown address (Fig. 1). Of the remaining 795 questionnaires, 537 were returned (response rate 67\%). In 34 cases, more than $50 \%$ of items were missing for all subscales and no scores could be calculated. Scores for at least one subscale could thus be calculated in 503 subjects (63\%; 242 men and 261 women) (Fig. 1). The highest response rate, $73 \%$, was found in the age groups 55-74 and 75-84.

Age-related differences were studied separately in men and women in the four age-collapsed groups (Fig. 2). For both men and women, hip function decreased with increasing age.

\section{Age-related differences in women}

The oldest age group (75-84 years) reported statistically significantly more disability than the youngest group (18-34 years) in all five subscales: Pain (72 vs. 91, $p<$ 


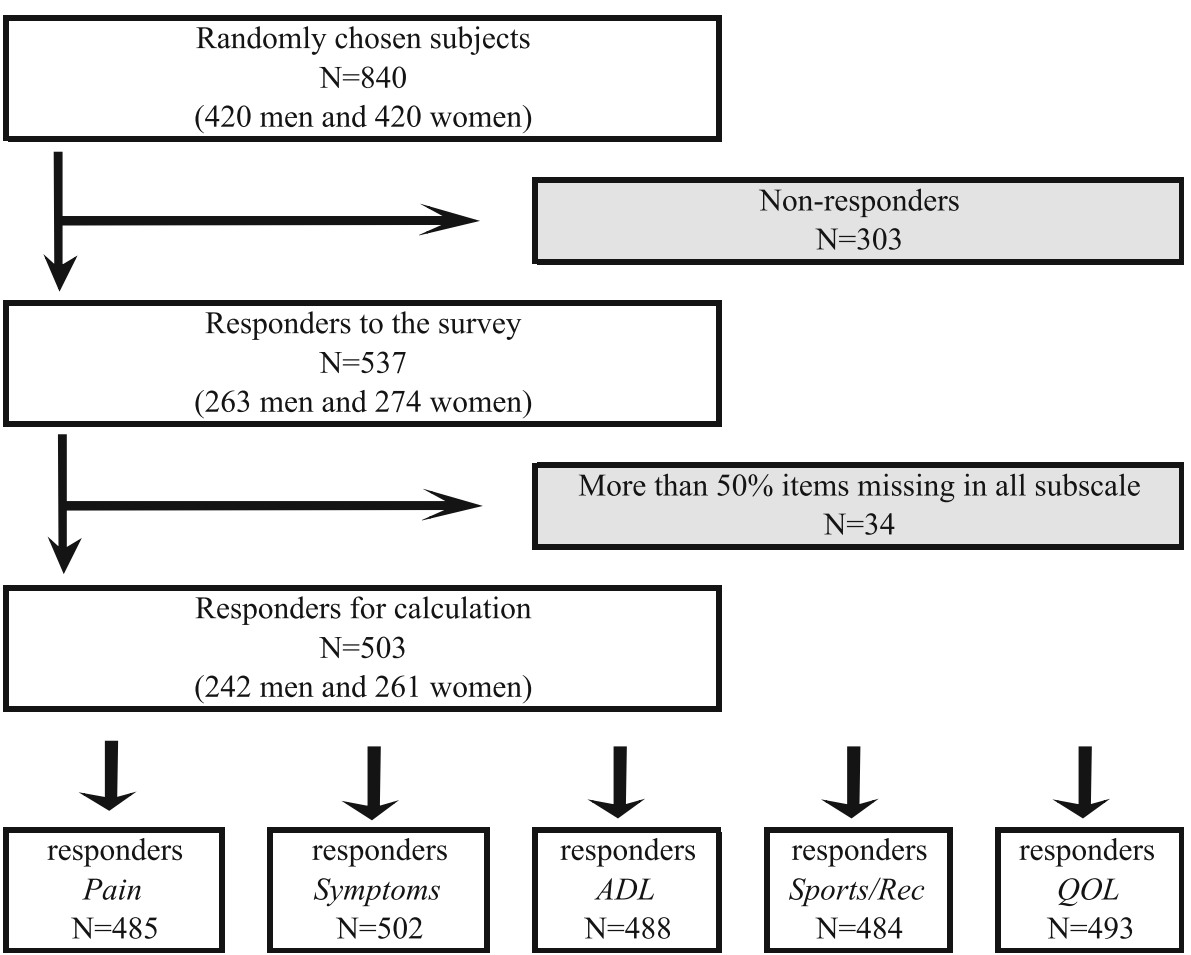

Fig. 1 Flow chart detailing the study procedure and formation of the patient cohort.

0.001 ), Symptoms (68 vs. $88, p<0.001$ ), ADL (69 vs. 93, $p<0.001$ ), Sport/Rec (56 vs. 91, $p<0.001$ ) and QOL (61 vs. $89, p<0.001)$.

Significant differences were also found in the subscales ADL (69 vs. $81, p=0.043$ ), Sport/Rec (56 vs. $75, p=0.017$ ) and QOL (61 vs. 77, $p=0.028$ ) between women in the two oldest age groups (75-84 years and 55-74 years) with more complaints in the oldest age group.

Significant differences were found between the oldest age group (75-84 years) and the age group 35-54 years in Pain (72 vs. 87, $p=0.007$ ), Symptoms (68 vs. $86, p=$ 0.001 ), ADL (69 vs. $88, p<0.001$ ), Sport/Rec (56 vs. 83, $p<0.001)$ and QOL (62 vs. $85, p<0.001)$ with more complaints in the oldest age group.

Between the age group 55-74 years and the youngest age group (18-34 years) significant differences were found in Symptoms (78 vs. 88, $p=0.026$ ), ADL (82 vs. 93, $p=0.012)$, Sport $/ \operatorname{Rec}(75$ vs. $91, p=0.011)$ and QOL (77 vs. $89, p=0.031$ ) with more complaints in the age group 55-74 years.

No significant differences were found between the age group 35-54 years and the youngest age group (18-34 years). (Table 1 and Fig. 2).

\section{Age-related differences in men}

Significant differences were found between the oldest age group (75-84 years) and the youngest age group (18-34 years) with more hip problems in the oldest age group in four subscales: Pain (83 vs. 96, $\mathrm{p}=0.03$ ), ADL (80 vs. $98, p=0.001)$, Sport/Rec (69 vs. 93, $p<0.001)$ and QOL (81 vs. 93, $p=0.036$ ).

Significant differences were also found between the age groups 75-84 years and the second youngest age group (35-54 years) in Sport/Rec (69 vs. 86, $p=0.016$ ), with more complaints in the oldest age group.

Between the second oldest age group (55-74 years) and youngest age group (18-34 years) significant differences were found in Pain (82 vs. 96, $p=0.002)$, ADL (83 vs. 98, p $<0.001)$, Sport/Rec (75 vs. 93, $p=0.001)$ and QOL (79 vs. 93, $\mathrm{p}=0.001)$ with more hip problems in the age group 55-74 years.

No statistically significant differences were found in any of the five subscales between the age group 75-84 and the age group 55-74 years, age groups 55-74 years and 35-54 years, or between the two youngest age groups (35-54 years and 18-34 years). (Table 1 and Fig. 2).

\section{Sex-related differences}

In the oldest age group, statistically significant differences between the sexes were found for.

Symptoms (68 vs. $80, p=0.019$ ) and QOL (61 vs. 81, $p=$ 0.001 ) where women had more hip problems than men. In the youngest age group, women had statistically significantly more hip problems than men in Pain (91 vs. 96, $p=0.003$ ), $\mathrm{ADL}$ (93 vs. $98, p=0.002$ ) and in QOL (89 vs. 93, $p=0.004$ ). 

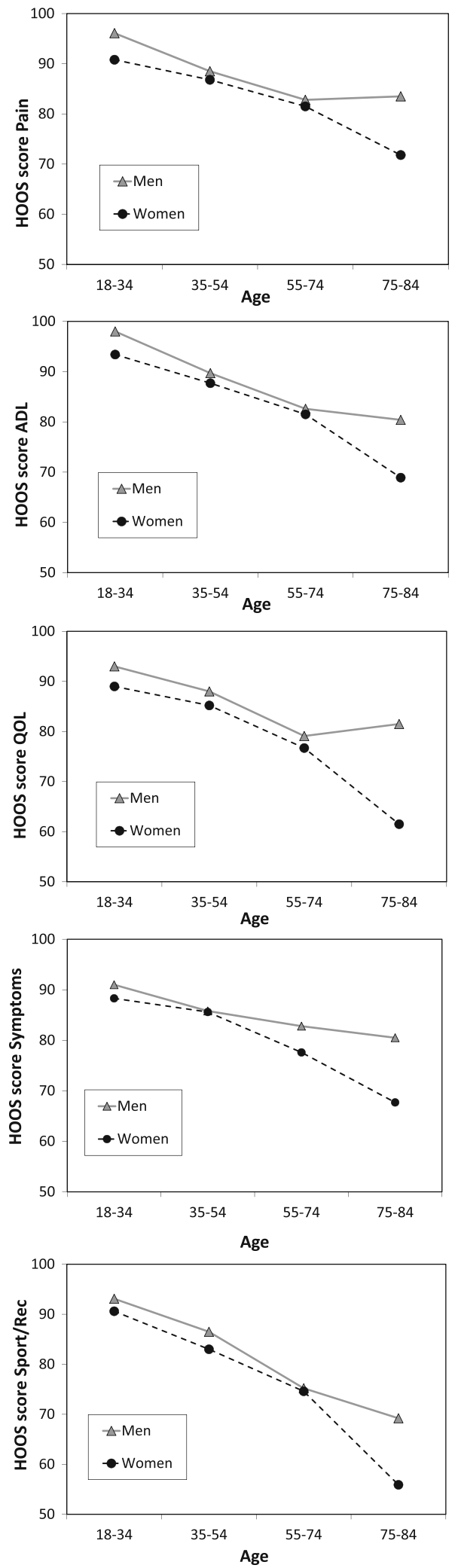

Fig. 2 Mean HOOS scores of the subscales Pain, Symptoms, ADL, Sports/Rec and QOL for men and women in different age groups.
No significant differences were found between the sexes in the age groups 55-74 years and 35-54 years. (Table 1 and Fig. 2).

\section{Discussion}

The main aim of this study was to establish reference data for the HOOS, a patient-reported outcome instrument for individuals with hip OA. To our best knowledge, this study is the first to report population-based reference data for the HOOS.

The difference in reported hip complaints between men and women was most pronounced in the oldest age group (75-84 years), with women reporting markedly more complaints than men, especially in QOL, where the difference was 20 points ( 81.5 vs. 61.5 points). In Pain, Symptoms, ADL and Sports/Rec the difference was $11.5-13.3$ points also indicating more complaints in women. In the youngest age group, women also reported more hip complaints than men in Pain, Symptoms and ADL.

These results differ from those in the KOOS study (a similar study population randomly chosen from the same national population in Skåne), where men aged 75-84 reported more complaints than both younger men and age-matched women for all subscales but Sport/Rec and women aged 75-84 reported fewer complaints than those aged 55-74 [13]. In agreement with the present study the prevalence of joint complaints was reported higher in women than in men and increases with age [22-24].

The differences between the age groups in women was most pronounced in QOL where the difference was 15.2 points (76.7 vs. 61.5 ) and in ADL 12.7 points (81.5 vs. 68.8) between the oldest 75-84 and the second oldest 55-74 age group with older women reporting more complaints.

The differences between the age groups in men were most pronounced in Sport/Rec where the difference was 12.3 points ( 86.5 vs. 74.2 ) between the age groups $35-54$ and $55-74$.

Similar to other population-based study cohorts, this group of individuals randomly selected from a general population certainly included individuals with osteoarthritis, other musculoskeletal disorders and comorbidities influencing their response to the HOOS questionnaire. It is known that musculoskeletal disorders affects women more commonly than men, and the prevalence increases with age [22].

We collected data from a wide age range and could therefore study the hip-related self-reported complaints across an adult population. However, although an acceptable response rate was acquired, we cannot disregard the fact that 33\% did not answer the questionnaire, and for whom we do not know the reasons. With missing values, there is always the possibility that the participants who declined to respond were too healthy or too sick to be interested, which would mean that the HOOS scores presented 
Table 1 Age-specific HOOS scores given as mean, standard deviation (SD), 95\% confidence interval (Cl) of the mean, and median, for woman $(\mathrm{W})$ ) and men $(\mathrm{M})$ in the different age groups

\begin{tabular}{lllll}
\hline Age group & $18-34$ & $35-54$ & $55-74$ & $75-84$ \\
\hline Pain & & & & \\
Wn & 63 & 76 & 80 & 35 \\
MeanSD & $90.8 \pm 15$ & $86.8 \pm 21.7$ & $81.5 \pm 23.9$ & $71.8 \pm 29.8$ \\
95\%CL & $87.1-94.5$ & $81.9-91.7$ & $76.3-86.7$ & $61.9-81.6$ \\
Median & 97.5 & 100 & 94.7 & 82.5 \\
Mn & 46 & 73 & 74 & 38 \\
MeanSD & $96.1 \pm 9.9$ & $88.5 \pm 19.9$ & $82.8 \pm 22.6$ & $83.5 \pm 24.3$ \\
95\%CL & $93.2-98.9$ & $83.9-93.1$ & $77.7-88$ & $75.8-91.3$ \\
Median & 100 & 100 & 92.5 & 98.8
\end{tabular}

Symptoms

$\begin{array}{lllll}\text { Wn } & 65 & 78 & 82 & 35 \\ \text { MeanSD } & 88.3 \pm 16.3 & 85.6 \pm 20.9 & 77.6 \pm 24.4 & 67.7 \pm 29.6 \\ \text { 95\%CL } & 84.3-92.2 & 80.9-90.2 & 72.3-82.9 & 57.9-77.5 \\ \text { Median } & 93.8 & 96.9 & 87.5 & 77 \\ \text { Mn } & 50 & 73 & 78 & 41 \\ \text { MeanSD } & 91 \pm 14 & 85.8 \pm 20.2 & 82.8 \pm 23.7 & 80.5 \pm 22.2 \\ \text { 95\%CL } & 87.6-95.1 & 81.2-90.4 & 77.5-88 & 73.8-87.3 \\ \text { Median } & 100 & 100 & 93.8 & 87.5\end{array}$

$\mathrm{ADL}$

\begin{tabular}{|c|c|c|c|c|}
\hline Wn & 64 & 77 & 80 & 34 \\
\hline MeanSD & $93.4 \pm 14.6$ & $87.7 \pm 22.2$ & $81.5 \pm 24$ & $68.9 \pm 32$ \\
\hline $95 \% C L$ & 89.8-97 & $82.8-92.7$ & $76.3-86.6$ & $58.1-79.6$ \\
\hline Median & 100 & 100 & 95.8 & 75 \\
\hline $\mathrm{Mn}$ & 50 & 71 & 75 & 38 \\
\hline MeanSD & $98 \pm 7.4$ & $98.7 \pm 19.5$ & $82.6 \pm 24.4$ & $80.4 \pm 28.7$ \\
\hline $95 \% C L$ & $95.7-99.8$ & $85.2-94.2$ & $77.1-88.1$ & $71.2-89.5$ \\
\hline Median & 100 & 100 & 95.2 & 98.8 \\
\hline \multicolumn{5}{|l|}{ Sport/Rec } \\
\hline Wn & 63 & 77 & 77 & 34 \\
\hline MeanSD & $90.6 \pm 19.4$ & $83 \pm 29.3$ & $74.6 \pm 32.3$ & $55.9 \pm 39.4$ \\
\hline $95 \% C L$ & 85.8-95.4 & $76.5-89.6$ & $76.4-81.8$ & $42.5-69.4$ \\
\hline Median & 100 & 100 & 91.7 & 58.3 \\
\hline $\mathrm{Mn}$ & 48 & 72 & 75 & 39 \\
\hline MeanSD & $93.1 \pm 20.7$ & $86.5 \pm 23$ & $75.2 \pm 33.5$ & $69.2 \pm 38.2$ \\
\hline $95 \% C L$ & $87.2-98.9$ & $81.2-91.8$ & $62.7-82.8$ & $57.2-81.2$ \\
\hline Median & 100 & 100 & 91.7 & 91.7 \\
\hline \multicolumn{5}{|l|}{ QOL } \\
\hline WN & 64 & 77 & 82 & 34 \\
\hline MeanSD & $89 \pm 17.4$ & $85.2 \pm 23.7$ & $76.7 \pm 28.3$ & $61.5 \pm 36.9$ \\
\hline $95 \% C L$ & $84.7-93.2$ & 79.9-90.5 & $70.6-82.9$ & $49.1-73.9$ \\
\hline Median & 100 & 100 & 90 & 67.5 \\
\hline $\mathrm{Mn}$ & 48 & 73 & 76 & 39 \\
\hline
\end{tabular}

Table 1 Age-specific HOOS scores given as mean, standard deviation (SD), 95\% confidence interval (Cl) of the mean, and median, for woman (W)) and men (M) in the different age groups (Continued)

\begin{tabular}{|cllll|}
\hline Age group & $18-34$ & $35-54$ & $55-74$ & $75-84$ \\
\hline MeanSD & $93 \pm 13$ & $88 \pm 20$ & $79.1 \pm 27.4$ & $81.5 \pm 25.7$ \\
95\%CL & $89-96.5$ & $83.4-92.6$ & $72.9-85.2$ & $73.5-89.6$ \\
Median & 100 & 100 & 93.8 & 100 \\
\hline
\end{tabular}

in this study could be an under- or over-estimation of the true size of the problem.

Despite the differences in item content in subscales between the HOOS LK1.0 and 2.0, the age- and sex-specific values in the population of this study should be applicable to both versions of the HOOS [17]. Five questions in the HOOS LK1.0 are not included in the HOOS LK2.0, but the content in these removed questions is included in other items in the HOOS LK2.0. Three items were moved from one subscale in the HOOS LK1.0 to another subscale in the HOOS LK2.0. The HOOS subscales scores are not dependent on the number of items in the respective subscales since the total score of each subscale is divided by the possible maximum score for the subscale [17].

\section{Conclusion}

Hip-related pain, symptoms, function of daily life and quality of life varied with age and sex in a population-based sample aged 18-84 years. These findings highlight the importance of using age- and sex-matched reference values in studies evaluating individuals with hip complaints.

\section{Abbreviations}

ADL: Activity limitations-daily living; OA: Osteoarthritis; QOL: Hip-Related Quality of Life; Sport/Rec: Sport and Recreation Function; the HOOS: The Hip disability and Osteoarthritis Outcome Score; the KOOS: The Knee injury and Osteoarthritis Outcome Score; THR: Total hip replacement; WOMAC: The Western Ontario and McMaster Universities Arthritis Index

\section{Acknowledgements}

We would like to thank Lars Wahlgren, Ulf Jakobsson and Sara Larsson Lönn for providing statistical know-how and guidance.

\section{Funding}

This study was funded by the Medical Faculty, Lund University, Lund, Sweden.

\section{Availability of data and materials}

Individual patient data will not be shared as consent for this was not obtained from participants. Data and materials available on request from the corresponding author.

\section{Authors' contributions}

AS conceived the study, participated in the study design, collected data and revised the manuscript critically for intellectual content. KL performed the statistical analysis and drafted the manuscript. EMR and LSL conceived the study and participated in the study design and manuscript revision. EEH helped draft the manuscript and revised the manuscript critically for intellectual content. All authors read and approved the final manuscript. 


\section{Ethics approval and consent to participate}

The Regional Ethical Review Board (Etiknämnden, Lund, Sweden) approved the study (LU 600-00). Informed consent were obtained from all individuals participating in the study.

\section{Consent for publication}

Not applicable.

\section{Competing interests}

The authors declare that they have no competing interests.

\section{Publisher's Note}

Springer Nature remains neutral with regard to jurisdictional claims in published maps and institutional affiliations.

\section{Author details}

${ }^{1}$ Department of Health Sciences, Lund University, Lund, Sweden. ${ }^{2}$ Department of Sports Science and Clinical Biomechanics, University of Southern Denmark, Odense, Denmark. ${ }^{3}$ Department of Clinical Sciences in Lund, Lund University, Lund, Sweden. ${ }^{4}$ Department of Clinical Sciences in Malmö, Lund University, Lund, Sweden.

Received: 2 October 2017 Accepted: 18 September 2018

Published online: 11 October 2018

\section{References}

1. March L, Smith EUR, Hoy DG, Cross MJ, Sanchez-Riera L, Blyth F, Buchbinder $\mathrm{R}$, Vost T, Woolf AD. Burden of disability due to musculoskeletal (MSK) disorders. Best Pract Res Clin Rheumatol. 2014;28:353-66.

2. Thorborg K, Roos EM, Bartels EM, Petersen J, Holmich P. Validity, reliability and responsiveness of patient-reported outcome questionnaires when assessing hip and groin disability: a systematic review. Br J Sports Med. 2010;44(16):1186-96.

3. Bellamy N, Buchanan W, Goldsmith CH. Validation study of WOMAC: a health status instrument for measuring clinically important patient-relevant outcomes following total hip or knee arthroplasty in osteoarthritis. Orthop Rheumat. 1988:1:95-108.

4. Klässbo M, Larsson E, Mannevik E. Hip disability and osteoarthritis outcome score. Scand J Rheumatol. 2003;32:46-51.

5. Nilsdotter AK, Lohmander LS, Klässbo M, Roos EM. Hip disability and osteoarthritis outcome score (HOOS)--validity and responsiveness in total hip replacement. BMC Musculoskelet Disord. 2003;4:10.

6. Malcolm TL, Szubski CR, Nowacki AS, Klika AK, lannotti JP, Barsoum WK. Activity levels and functional outcomes of young patients undergoing total hip arthroplasty. Orthopedics. 2014;37(11):983-92.

7. Ageberg E, Nilsdotter A, Kosek E, Roos EM. Effects of neuromuscular training (NEMEX-TJR) on patient-reported outcomes and physical function in severe primary hip or knee osteoarthritis: a controlled before-and-after study. BMC Musculoskelet Disord. 2013;14:232.

8. Satoh M, Masuhara K, Goldhahn S, Kawaguchi T. Cross-cultural adaptation and validation reliability, validity of the Japanese version of the hip disability and osteoarthritis outcome score (HOOS) in patients with hip osteoarthritis. Osteoarthr Cartil. 2013;21(4):570-3.

9. Kemp JL, Collins NJ, Roos EM, Crossley KM. Psychometric properties of patient-reported outcome measures for hip arthroscopic surgery. Am J Sports Med. 2013:41:2065-73.

10. Ornetti P, Parratte S, Gossec L, Tavernier C, Roos EM, Guillemin F, Maillefert JF. Cross-cultural adaptation and validation of the French version of the hip disability and osteoarthritis outcome score (HOOS) in hip osteoarthritis patients. Osteoarthr Cartil. 2010;18:522-9.

11. Arbab D, van Ochten JHM, Schnurr C, Bouillon CB, König D. Assessment of reliability, validity, responsiveness and minimally important change of the German hip dysfunction and osteoarthritis outcome score (HOOS) in patients with osteoarthritis of the hip. Rheumatol Int. 2017:37:2005.

12. Trathitiphan $W$, Paholpak $P$, Sirichativapee $W$, Wisanuyotin $T$, Laupattarakasem P, Sukhonthamarn K, Jeeravipoolvarn P, Kosuwon W. Cross-cultural adaptation and validation of the reliability of the Thai version of the hip disability and osteoarthritis outcome score (HOOS). Rheumatol Int. 2016;36(10):1455-8.

13. Paradowski PT, Bergman S, Sunden-Lundius A, Lohmander LS, Roos EM Knee complaints vary with age and sex in the adult population. Population- based reference data for the knee injury and osteoarthritis outcome score (KOOS). BMC Musculoskelet Disord. 2006;7:38.

14. McKay MJ, Baldwin JN, Ferreira P, Simic M, Vanicek N, et al. 1000 norms project: protocol of a cross-sectional study cataloging human variation. Physiotherapy. 2016;102:50-6.

15. Villadsen A, Overgaard S, Holsgaard-Larsen A, Christensen R, Roos EM. Immediate efficacy of neuromuscular exercise in patients with severe osteoarthritis of the hip or knee: a secondary analysis from a randomized controlled trial. J Rheumatol. 2014;41(7):1385-94.

16. Ware JK, Owens BD, Akelman MR, Karamchedu NP, Fadale PD, Hulstyn MJ Shalvoy RM, Badger GJ, Fleming BC. Preoperative KOOS and SF-36 scores are associated with the development of symptomatic knee osteoarthritis at 7 years after anterior cruciate ligament reconstruction. Am J of Sports Med. 2018;46(4):869-75

17. http://www.koos.nu/

18. Roos EM, Lohmander LS. The knee injury and osteoarthritis outcome score (KOOS): from joint injury to osteoarthritis. Health Qual Life Outcomes. 2003;1:64.

19. Roos EM, Roos HP, Ekdahl C, Lohmander LS. Knee injury and osteoarthritis outcome score (KOOS)--validation of a Swedish version. Scand J Med SCi Sports. 1998:8(6):439-48.

20. Roos EM, Roos HP, Lohmander LS, Ekdahl C, Beynnon BD. Knee injury and osteoarthritis outcome score (KOOS)--development of a self-administered outcome measure. J Orthop Sports Phys Ther. 1998;28(2):88-96.

21. Altman DG. Practical statistics for medical research. London: Chapman\&Hall; 1991.

22. March L, Smith EUR, Hoy G, Cross MJ, Sanchez-Riera L, Blyth F, Buchbinder $R$, Vos T, Woolf AD. Burden of disability due to musculoskeletal (MSK) disorders. Best Pract Res Clin Rheumatol. 2014;28:353-68.

23. Thiem U, Lamsfuß R, Günther S, Schumacher J, Bäker C, Endres HG, Zacher J, Burmester GR, Pientka L. Prevalence of self-reported pain, joint complaints and knee or hip complaints in adults aged $\geq 40$ years: a cross-sectional survey in Herne, Germany. PLoS One. 2013;8(4):e60753.

24. Turkiewicz A, Peterson IF, Björk J, Hawker G, Dahlberg LE, Lohmander LS, Englund M. Current and future impact of osteoarthritis on health care: a population-based study with projection to year 2023. Osteoarthr Cartil. 2014;22:1826-32.

Ready to submit your research? Choose BMC and benefit from:

- fast, convenient online submission

- thorough peer review by experienced researchers in your field

- rapid publication on acceptance

- support for research data, including large and complex data types

- gold Open Access which fosters wider collaboration and increased citations

- maximum visibility for your research: over $100 \mathrm{M}$ website views per year

At $\mathrm{BMC}$, research is always in progress.

Learn more biomedcentral.com/submission 